\title{
Modularity, Industry Life Cycle and Open Innovation
}

\author{
Muge Ozman'
}

\begin{abstract}
This paper discusses the incentives behind, and effects of open innovation in different stages of an industry life cycle. It argues that in the beginning of an industry life cycle, open innovation policies usually serve the dual purpose of exploring distant knowledge sources, and exploiting potential network effects to strengthen the installed base of a technology. In the later phases of the industry life cycle, after the emergence of a dominant design, open innovation incentives and effects depend largely on the product system architecture. Modularity at different parts of the product system is an important dimension which influences the types of open innovation strategies implemented by firms.
\end{abstract}

Keywords: : Open innovation; industry life cycle; modularity; network effects.

\footnotetext{
- The research leading to this paper was carried out in the context of the joint research project MODEUS / UBIMEDIA, between Institut Telecom (France) and Alcatel-Lucent Technologies.

I Institut Telecom - Telecom Ecole de Management 9 Rue Charles Fourrier 910II Evry, France and Bureau d'économie théorique et appliquée (BETA) Universite Louis Pasteur 6I avenue de la Forêt Noire 67085 Strasbourg France/ e-mail : muge.ozman@it-sudparis.eu Tel: +331607647085
} 


\section{Introduction}

Open innovation broadly refers to the creation, development and maintenance of channels through which firms access external sources of knowledge and reduce the barriers of access to their own knowledge bases (Chesbrough, 2003). Open innovation emphasizes the "collective" nature of the innovation process, which has been the central premise of the innovation literature since the 1980s (Nelson and Winter, 1982; Allen, 1983).

Until recently, our knowledge about open innovation has been largely shaped by examples from knowledge intensive sectors of the economy in which there is rapid innovation. Various industries like electronics (Christensen et al., 2005), computers (Chesbrough, 2003), software (West and Scott, 2006), pharmaceuticals (Dodgson et al., 2006) have attracted widespread attention. This perception of open innovation is recently changing. Some more recent case studies (Aylen, 2010) show how open innovation has been used in other industrial contexts (Chesbrough and Crowther, 2006). Although the term open innovation is not always explicitly used, one can certainly find historical case studies which emphasize the importance of external relations of the firm (Allen, 1983).

Although several authors have stressed that open innovation should be analysed in a contingent framework (Gassman, 2008), there exist few, if any, studies to make a systematic distinction between the incentives behind, and effects of open innovation in different industrial contexts. Some questions which inspire further research along these lines are, whether there are any systematic differences between incentives to pursue open innovation in the context of steel mills in the mid 20th century, and in the ICT sector of the recent years? Why are the most commonly used open innovation practices in pharmaceuticals sector different from those used in the computer industry?

This paper is an initial attempt to understand the systematic differences between open innovation practices in different industrial contexts. For this purpose, the paper focuses on the stage in the industry life cycle and the architecture of the product system. The paper shows that in the beginning of an industry life cycle, the incentives behind open innovation are different than in the later phases. The ways in which firms interact with each other in the early phases influence the emerging architecture of the product system. After the emergence of a dominant design, it is this architecture which shapes the open innovation incentives and effects later on. We demonstrate these arguments both by referring to previous literature, and by giving examples from a variety of industries. In doing so, the central feature of a product system is taken as modularity.

The paper is organized as follows. The second section focuses on the early phases of industry life cycle, before the emergence of a dominant design. It highlights the most common open innovation practices used in different industries, and the benefits of open innovation. In the third section, the definition of product system architecture is made, in relation to the concept of modularity. In the fourth section, the widely used open innovation policies in later phases of the industry life cycle are discussed in relation with the characteristics of the product system architecture. Concluding remarks follow.

\section{Open Innovation in the Early Phases of an Industry Life Cycle}

The technological and market uncertainty in the beginning of an industry life cycle is usually accompanied by increased knowledge exchange between firms, in which experts develop a common language which is not yet codified (Rosenkopf and Tushman, 1998; Rowley et al., 2000). Through these networks new knowledge is continuously created and diffused. These networks contribute to the emergence of a dominant design (Utterback, 1994). Because the product system's architecture is in the phase of development, firms closely follow technological developments taking place beyond their boundaries, to explore novelties that may shape the future of the product system (March, 199I). In this phase, network positions which permit access to knowledge from distant sources is preferred by firms for exploration purposes (Rowley et al., 2000). In this stage, one of the incentives behind open innovation is exploring potentially important technical expertise which the firm may not be yet endowed with.

It is also a common practice to interact with a wide variety of external actors in the industry (customers, other firms, suppliers, research institutes, etc.) early on, to strengthen the installed base of the firm's technology. Network effects refer to the increase in the value of consuming a particular product or service, when either 
a) the more are the users of the product or service, as in the case of physical network goods (Arthur, 1989; David, 1985; Economides and Salop, 1992) or b) the more are the complementary products offered by the producers, in terms of the variety of available products (whereby the possibilities of mixing and matching increase (Katz and Shapiro, 1985). Early interactions with external actors give firms the possibility to make use of network effects in strengthening a particular platform and increase the possibility of its adoption as the market matures.

One of the ways in which firms can create opportunities to benefit from network effects is through making their systems modular. A modular technology system facilitates the emergence of a variety of specialized complementary good and service providers. This, in result, can create a positive feedback loop which strengthens the market share of the proprietor of the core technology. For example during the 1980s, Intel's product development strategy favored the design of a modular $\mathrm{PCl}$ (peripheral component interface) to support the speed of its future microprocessors, which was made available freely and open to everyone (Gawer and Cusumano, 2002). The development of the $\mathrm{PCl}$ shaped the architecture of the dominant computer design. Behind the widespread adoption of $\mathrm{PCl}$ lie the external relations of Intel in diffusing its standard, and their modular design.

Most of the open innovation activities in the beginning of industry life cycles serve the dual purpose of managing network effects and exploration jointly. Through exploration, firms recombine distant knowledge with their own. The recombination of such diverse technical expertise ultimately shapes the product system architecture (Hargadon and Sutton, 1997). In addition, through investing in young firms who might be future supporters of the firms' technology, firms have the chance to enlarge their installed base. Chesbrough (2003) explains how Intel was investing in young and dynamic firms who could in the future strengthen its own microprocessor market by providing complementary systems.

Real world examples which demonstrate these points are numerous. One of the earliest examples can be given from the automobile industry. In 1922, the joint venture between Ford Motor Company and Pilkington Brothers Glass, and UK based glass company, resulted in a process innovation whereby the previously separated casting and annealing processes were linked. This innovation resulted in a considerable productivity increase in plate glassmaking, which ultimately strengthened the market for gasoline powered automobile design (Utterback, 1994). By adopting an open innovation policy, Ford Motor Company was not only exploring technical expertise beyond its own, but also strengthening the market for gas powered vehicles. From the perspective of Pilkington Glass, the complementary knowledge to its own expertise came from one of the main users of the technology, which is from outside its industry (Von Hippel, 1988). The activities of both companies can be given as examples of open innovation.

In the early phases of the computer industry, there are countless examples of open innovation, in which exploration and network effects were the main facets. For example, IBMs leader position in the computer industry was very effective in the shift from $150 \mathrm{~mm}$ to $200 \mathrm{~mm}$ wafers, used in the fabrication of integrated circuits. IBM was collaborating with major equipment suppliers and invested heavily in research to this end. Having early access to a critical equipment resulted in an active role in setting standards, which was the source of competitive advantage in the market (Chesbrough, 2003). Another example is the case of Sun Microsystems workstation design (Garud and Kumaraswamy, 1993). The authors show how Sun Microsystems, through the adoption of an open standard and by facilitating the access of other firms to its standard, was able to expand its market share through network effects.

Another example can be given from medical equipment industry. Swallowable camera pill was a new technology in the beginnings of 2000s (Schilling, 2008). In this case, open innovation involved continuous interactions with hospitals who were the main users. Through these interactions, Given Imaging, who was the developer of the pill, was not only learning in-depth about user needs and involving them in the product development phase, but also it was increasing the switching costs to another technology system, and strengthening its installed base early on.

The different types of interactions that we present above ultimately serve the dual effect of learning by all parties involved, and relatedly the strengthening of a technology system through network effects. These open innovation activities shape the evolving product system architecture. 
Nevertheless, it should be noted that firms may also have increased incentives to perform in house research in the beginning of an industry life cycle. In house research serves two purposes. Firstly, firms try to increase their absorptive capacity, as a means to facilitate their exploration activities (Cohen and Levinthal, 1990). Secondly, firms might find it beneficial to diversify their activities for initial offering of complementary products to their core technologies, so as to strengthen their installed base in the early phases. In this case, if a firm lacks the necessary capabilities to supply complementary products, it can acquire competences through various agreements ranging from to mergers and acquisitions, R\&D agreements, etc

Towards more mature phases of an industry life cycle, the product system is being shaped. Below we discuss how this architecture has an effect on the open innovation policies that are to be practiced by firms in later phases of the life cycle. The next section briefly explains the product system architecture.

\section{Architecture of Product Systems}

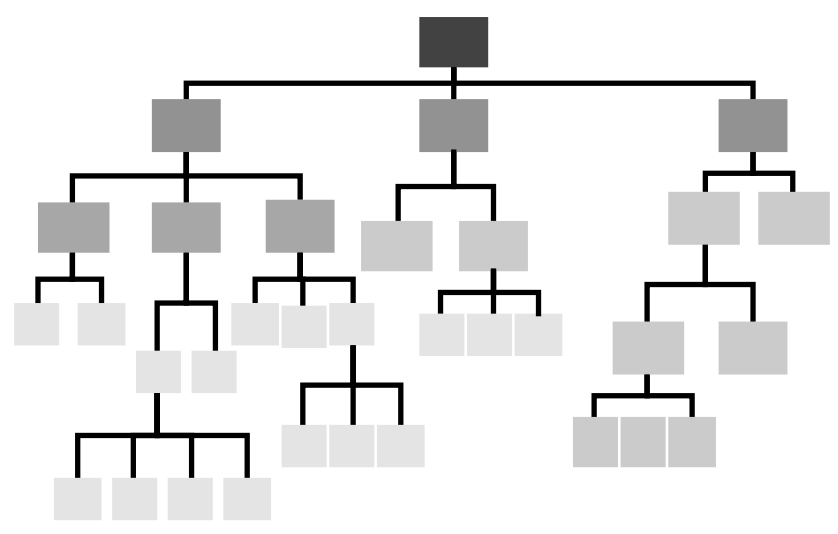

Figure I A Product System Architecture

\section{Product Systems as Nested Hierarchies}

Figure I represents a product system as a nested hierarchy, with increasing level of disintegration as one goes down. In the uppermost level of architecture, the widest possible set of goods and services to accomplish an intended function by the final consumers are placed. Viewed in this way, the product system for a gas powered vehicle includes not only the components of the vehicle itself (which are placed in lower levels) but also the transportation infrastructure, auto repair stations, gasoline stations and so on (which are placed in upper levels of the hierarchy).
Therefore, in the upper levels are placed the complements of a core technology (or technologies, if there is more than one standard which prevail in the market), among which consumers can form their own configurations. As one moves down the hierarchy, the products are further divided into assemblies, subassemblies, and components. In these levels, modules require more specialized knowledge and skills to be integrated and disintegrated, as compared to the upper levels of the hierarchy where modules are loosely connected to each other. The location of firms in this architecture, as far as their in-house activities are concerned, shapes their open innovation activities. Modularity of the system has a key role in this sense.

\section{Modularity: An Overview}

In the framework of industrial production systems, the concept of modularity is applicable mostly to assembled products. The origins of its formalization date back to Herbert Simon's (1962) analysis of managing complex systems by splitting them into modules. Alexander (1964) uses it as one of the building blocks of his theory in urban planning and product design. According to Schilling (2000: p. 312) modularity is a "continuum describing the degree to which a systems components can be separated and recombined...". Ulrich (1995) defines modularity as the one-to-one mapping between components and the functions of a system. Through modularity end users can generate additional value through mixing and matching components to satisfy different functional requirements. In this way modularity of the system can be a source of product variety for the users.

The producers can benefit from modular designs through increased efficiency. Different product designs can be created using a few platforms (see for example, Sanderson and Uzumeri (1997) for Sony's Walkman; Utterback et al. (2006) for Black and Decker and Meyer et al. (1997) for heart monitoring machines). Modularity has implications for both the performance of product systems, as well as organizational structure of industries and firms.

As far as performance is concerned there are various views. As a design rule, one point of view underlines that optimizing the performance of subsystems does not necessarily (and in most cases does not) optimize the performance of the system as a whole (Utterback et al., 2006; Alexander, 1964). On the other hand, modular product architectures permit independent innovations to be applied in different modules, without having to change 
J. Technol. Manag Innov. 20II,Volume 6, Issue I

all parts of the system (Baldwin and Clark, 1997, 2000; Langlois and Robertson, 1992). One of the implications of such independence between modules maybe a technology landscape whereby radical innovations are harder to pursue and incremental innovations become the dominant form of innovation (Fleming and Sorenson, 2003)

As far as the impact of modularity on organizational form is concerned, one point of view underlines that modular product systems are accompanied by an increasing autonomy of organizations and the loose coupling between them (Sanchez and Mahoney, 1996; Langlois and Robertson, 1992). On one hand, this will induce increased interactions among firms (Pavitt, 2005), but on the other hand, to the extent that the modules are kept proprietary by a systems integrator and interfaces are explicitly provided to suppliers in the form of clear blue prints, the extent of learning will depend on the assemblers strategy of interaction with suppliers (Mikkola, 2003; Pavitt, 2005). In these interactions, evidence shows that closer relationships with suppliers which permits the exchange of tacit knowledge contributes to the learning process, and joint product design results in the improvement in the performance of the overall product architecture (Sobrero and Roberts, 2002).

It is a common practice in the current literature to categorize some industries as modular. For example, according to Sanchez and Mahoney (2003) modular systems are automobiles, airplanes, and consumer electronics and the similar. However, this depends on the level of analysis selected. From a broader perspective, all product systems are modular in one or more levels. This is because the range of complementary goods and/ or services provided in the market can be taken as the modules of a larger product system. Automobile industry is not only modular in the manufacturing phase, but also modular in the whole system of gas powered vehicles. Some of the modules of this technology system then are auto repair stations, petrol stations, spare parts providers, roads and highways. But the modules in the manufacturing phase of the automobile are the brake system, the speedometer, the outer shell etc. In terms of Figure I, then, the upper parts of the hierarchy correspond to this broader perception of the product system. The lower parts correspond to the further disintegration of one of the components. Below we explain how the hierarchical representation of the system architecture may shape type of open innovation strategies implemented by firms.

\section{Industry Life Cycle: Mature Phase}

In the mature phases of the industry life cycle, a dominant design emerges and with its emergence, the assemblies, subassemblies and components of the product system, as well as the production processes are largely shaped. In this phase, firms gain familiarity with the dominant design, and complementary products which support the existing dominant design emerge (Abernathy and Utterback, 1978). In addition, the innovation shifts from product to process innovations.

As far as their implications for open innovation are concerned, we distinguish between four possible shapes of the product system hierarchy; modular final products, modular manufacturing systems, non-modular final products, and non-modular manufacturing systems. Here, the final products refer to the upper parts of the product system hierarchy where consumers can mix and match between different options. We analyse how open innovation is influenced depending on the degree of modularity of the final products. On the other hand, the manufacturing systems correspond to the lower parts of the product system hierarchy where specialized skills are required for integration, design and development. Then we investigate, how the modularity in the production level influences open innovation policies by firms.

\section{Open Innovation and Modularity in Final Products}

Modular product architectures in downstream markets may result in a variety of complementary products supplied by different vendors. Schilling (2000) provides an analysis of the factors which influence inter-firm product modularity. She mentions that the utility derived from mixing and matching by final consumers, heterogeneity of producers and users, synergistic specificity of the product system, the technical knowledge of users all influence the extent to which different vendors provide complementary products.

In some industries, even after the emergence of a dominant design, two or more incompatible standards coexist. The video games industry is a good example in this sense. The beginnings of this industry date back to 1950s (Kemp, 200I). Until the 1990s a variety of game console designs dominated the market in alternating periods. The 1990s seems to have marked the emergence of a dominant design with the modern game console. Currently, the three main players in the market are Sony with the 
Play Station, Microsoft with the Xbox, and Nintendo with the Wii. Although the overall product system architecture is similar for these consoles, the compatibility between them depends on the games available. Another well known example is the compatibility between operating systems and software applications.

Industries in which the modularity of final products generate significant value, as in video games and computer software, one of the most common incentives behind open innovation is to strengthen the market share of their technology vis a vis others. Strategies concerned with distribution, alliance and marketing can greatly influence the firm's success in expanding its installed base through network effects (Schilling, 1999). An obvious example is Microsoft's relationship management with software producers to encourage the design of a rich variety of software compatible with the Windows operating system.

When there is a potential of capturing additional value through network effects, firms may also be involved in partnerships with other firms to increase the modularity of their systems. The partnerships of Apple with major recording companies permitted offering individual songs for purchase through its well known online iTunes network, which was one of the factors behind the widespread adoption of the iPod music player.

In other cases, firms may be involved in alliances with other firms to support a standard jointly (Hill, 1997). An early example is the VHS videocassette format, where Matshushita licensed its technology to a range of other consumer electronics companies, which ultimately contributed to the widespread acceptance of their technology. In a similar vein, the partnership between Sony and Philips to combine their compact disk standards into one resulted in a bandwagon effect whereby the joint $C D$ audio player technology was soon to be adopted by the whole market.

In general, modularity of the system is a critical determinant of how the complementary products will fit together. Increasing degrees of modularity increases the chances of a larger number of complementary products, and also augment the extent to which firms can benefit from open innovation through network effects.

\section{Open Innovation in Modular Manufacturing Systems}

In most product systems, after the emergence of a dominant design, innovation happens usually in the component or process level (Henderson and Clark, 1990; Utterback, 1994). As firms start accumulating experience in the production process, they gain system level experience about how components work together. In this phase, to the extent that the manufacturing system is modular, radical innovations may be more difficult to pursue (Fleming and Sorenson, 2003).

Baldwin and Clark (1997) state that modularity facilitates outsourcing, which constitutes an opportunity for firms to access technical expertise that is relevant for their product system, but which they may not be endowed with. Nevertheless, this does not mean that the extent of learning from other firms will be higher with increasing modularity. On the contrary, clearly defined interfaces can augment the autonomy of producers, and may in fact reduce knowledge flows between firms (Pavitt, 2003). In this sense, the ability of the firm to make use of the knowledge of others largely depends on the openness of the management to external sources of knowledge. Once an open culture is maintained within the organization, there exist a myriad of relationships in addition to outsourcing, which the firm can be involved in. Automobile industry is a very good example to demonstrate how open innovation works in modular manufacturing systems.

Supplier relationships in modular product systems are an important opportunity for firms to deepen their component level, and sometimes system level knowledge. In complex product systems like automobiles millions of components are integrated, each requiring specialized knowledge and skills. As a result organizational relationships range from arms length supplier relations to informal and close-knit ties with them in the form of joint module designs. In general, as far as learning effects are concerned, the more intensive are the interactions between suppliers and integrators, the more opportunities are there for learning. The difference in managerial approach between Japanese and American automobile firms are frequently mentioned; while Japanese firms mostly outsource "black box" parts which permit increased knowledge flows between firms, American firms outsource "detailed controlled" parts whereby learning opportunities are more limited (Clark and Fujimoto, 1991; Womack et al., 1990; Mikkola, 2003). 
Joint product development agreements with suppliers are one of the common open innovation activities of firms facing modularity in upstream markets. These interactions usually happen in the subsystem level, incorporating improvements in the design of components. The sources of architectural innovations on the other hand, which redefine the interfaces between subsystems, are usually young firms (Abernathy and Utterback, 1978). For example the growing importance of energy efficiency in automobiles have increased the importance of flexible young firms who have the technical capabilities to provide radical solutions, as compared to the capabilities of incumbent firms, whose firm-level routines are largely structured according to the traditional automobile design (Mann, 2009).

In other cases, firms are involved in relationships with each other in the supply chain to reduce the costs and increase the speed of new product introduction to the market. In relatively mature industries, access to distribution channels and reduction of the innovation period are common incentives behind inter-firm relations (Hagedoorn 1993).

Global production networks in the textile industry are frequently mentioned in this sense. Similarly, in the fashion industry, the division of labour among a group of firms is accompanied by persistent networks, through which firms develop a sense of trust and knowledge sharing (Uzzi, 1997).

\section{Open Innovation in Non-Modular Final Pro- duct Markets}

The existence of complementary products in the final markets is usually a matter of degree. Hardly there exists any industry in which a single firm provides all complementary products of the product system. Nevertheless, in some industries, complementary products have little added value for consumption. For example, when the fashion industry as a whole is taken as a product/service system, complementary modules range from specialized press, fashion shows, fashion channels on TV, clothing brands, and so on. However, for most people there is little, if any additional utility derived from consuming these complementary products. Examples of product systems in which the final modules of the system generate relatively less utility are food industry, entertainment industry, toy industry, publishing, pharmaceuticals, sports equipment, restaurant chains, etc.
Still, there exist various incentives behind open innovation in these industries, which are different from industries which are characterised by strong modularity in final markets. Foremost, open innovation policies are commonly used to expand the market share of firms, nationally or internationally. For example, toy industry and food industry has long used licenses from various entertainment companies to use as main characters in their products. The textile company Inditex (who owns the clothing chain Zara) uses joint ventures to enter into new markets.

Usually in these interactions, there are few knowledge flows between firms, so they might not be suitable examples in the context of open innovation. But in some cases, such alliances may take place to create a new product or technology which combines the technical expertise of the parties involved. In these cases, firms also have the chance to access distant capabilities other than their own, and depending on success, they may mark the beginning of a new technology cycle.

A recent example is the joint research between a sportswear company Nike and the computer giant Apple, aimed at designing smart jogging shoes, in which running performance can be recorded on the users ipod through sensors placed in the shoe. Through this joint research both companies not only explored knowledge in a field that is completely different than their own, but also they could benefit from the mutual network effects. Conde Nast, one of the largest publishing houses has announced a strategic alliance with Adobe for creating technologies that allows the company to design and produce new generation of digital magazines. The current era of digitalization of content has created even larger opportunities for firms operating in traditional industries to make use of network effects and explore knowledge that is very different than their own.

\section{Open Innovation in Non-Modular Manufacturing Industries}

In process-based industries with high economies of scale, like steel, glass, cement, petroleum refining, pharmaceuticals, opportunities for outsourcing is more limited than the modular manufacturing systems that were mentioned above in section 4.2. Nevertheless case studies in these industries reveal that, there exist significant motives for open innovation. 
One of the initial studies which emphasise the importance of learning through partnerships in biotechnology is by Powell et al. (1996). In biotechnology industry, the knowledge base is widely dispersed and the collaborations are mostly characterized by the alliances among the large and established pharmaceutical firms, which offer market access opportunities, and small firms' scientific and technical contributions (Arora and Gambardella, 1990; Walker et al., 1997; Shan et al., 1994).

Access to external knowledge has been an important motive behind open innovation in steel industry as well (Leonard Barton, 1992; Rowley et al., 2000). Similarly, the history of glass industry witnessed a wide array of external relations for the purpose of accessing external capabilities (Utterback, 1994).

Finally, one of the most common open innovation practices in process based industries has been user innovation. In the case of pharmaceuticals, for example, Procter and Gamble has initiated a systematic program through which customers participate in finding solutions to particular problems (Dodgson et al., 2005). Similar practices have been observed in the steel industry, as revealed by the case study of Nakamura and Ohashi (2008).

\section{Concluding Remarks and Directions for Future Research}

In this paper, common open innovation policies exercised by firms in different stages of the product life cycles are explored, supported by historical examples from a variety of industries. The main premise of the paper is that, the incentives behind, and the effects of open innovation largely depend on the extent of modularity of the product system, at the level in which the firm operates. In accordance with this, one of the implications of the arguments developed above is that, firms should have a very well understanding of the architecture of the product system in which they are positioned. In strategic management literature, the product system architecture which is used here is used in a similar vein as the value chain (Porter, 1998). While the essence of the value chain analysis is concerned with the value added in various levels, this paper argues that it is the physical architecture of the product system which determine the potential business models that firms develop, and their incentives behind being engaged with other actors in their ecosystem.
A summary of how the different stages of the product system architecture influences open innovation can be seen in Table I. In the early phases of industry life cycle, the dominant design has not yet emerged. In this phase, firms are involved in a range of open innovation activities which aim at increasing the installed base of their technology system. Accompanying these interactions is an important effect of open innovation: firms develop their knowledge and capabilities in fields that are distant from their own, yet strategically important for the future of the product system.

With the emergence of a dominant design, if the final products are highly complementary and modular, network effects is an important incentive in open innovation. If the level of modularity is in manufacturing phase of the product system, then relationships with suppliers have a critical importance to access external knowledge. These relationships usually involve component level innovations. Firms may also prefer to construct linkages with distant firms for the purpose of developing new products, but in which they lack expertise.

Finally, evidence shows that open innovation have been widely used in industries whose products are non modular. These industries are mostly process based manufacturing industries, like steel, glass, cement, pharmaceuticals and so on. User innovation, research partnerships for new processes, and access to distribution channels are important incentives behind open innovation in these cases.

The arguments developed in this paper do not claim to provide a comprehensive coverage of the linkage between product system architecture and open innovation, which involves far more complex dimensions beyond the issues raised here, depending on the industry considered. Nevertheless, as the title also suggests the aim of the paper is to draw attention to the significance of the nature of products, and the knowledge base underlying them in shaping open innovation. The current literature on open innovation largely lacks a systematic comparison of different product systems as far as their impact on firm behaviour is concerned. Rather, it is full of case studies which examine open innovation in a given product system. For sure, there remains many questions to be addressed on an empirical level, to have a better understanding of the complex relationship between the nature of product systems and open innovation in future research. 
J. Technol. Manag Innov. 20II,Volume 6, Issue I

\begin{tabular}{|c|c|c|c|c|}
\hline Industry Context & Open Innovation & Network Effects & $\begin{array}{l}\text { Access To } \\
\text { External } \\
\text { Capabilities and } \\
\text { Learning }\end{array}$ & $\begin{array}{c}\text { Market } \\
\text { Expansion }\end{array}$ \\
\hline \multirow[t]{4}{*}{ Early Phase of Life Cycle } & Licensing agreements to diffuse the core technology & + & - & + \\
\hline & $\begin{array}{l}\text { Investments in young firms to support the provision of } \\
\text { complementary products to the firms technology system }\end{array}$ & + & + & + \\
\hline & $\begin{array}{l}\text { Investments in major equipment suppliers to increase the } \\
\text { installed base of the core technology }\end{array}$ & + & + & + \\
\hline & Joint product development to have access to distant knowledge & - & + & - \\
\hline \multicolumn{5}{|l|}{ Mature Phase of Life Cycle } \\
\hline \multirow[t]{3}{*}{ Modular Final Products } & Complementary goods providers management & + & +- & + \\
\hline & User learning & +- & +- & + \\
\hline & Alliances to strengthen a standard & + & +- & + \\
\hline \multirow[t]{2}{*}{ Modular Manufacturing Systems } & $\begin{array}{l}\text { Supply chain relationships ranging from joint product } \\
\text { development, joint ventures, research partnerships. }\end{array}$ & +- & + & + \\
\hline & Partnerships to ensure fast market delivery & - & +- & + \\
\hline \multirow[t]{4}{*}{ Non Modular Systems } & User innovation & +- & + & + \\
\hline & Access to distribution channels & +- & +- & + \\
\hline & Licenses for marketing & +- & - & + \\
\hline & Joint process development & - & + & - \\
\hline \multicolumn{5}{|c|}{$\begin{array}{l}\text { "+": usually a direct impact } \\
\text { "+-": may or may not have the corresponding effect, depending on the context } \\
\text { "-": usually no direct impact }\end{array}$} \\
\hline
\end{tabular}

Table I 


\section{References}

ABERNATHY, W.J and Utterback, J.M (1978). Patterns of Industrial Innovation, Technology Review, 80(7): 40-47.

ALLEN, R. (1983). Collective Invention. Journal of Economic Behavior and Organization. 4: I-24.

ALEXANDER, C. (1964) .Notes on the Synthesis of Form. Cambridge, Massachusetts: Harvard University Press.

ARORA, A. and Gambardella, A. (1990). Complementary and External Linkages: The Strategies of the Large Firms in Biotechnology. Journal of Industrial Economics, 36I-379.

ARTHUR, B. (2009). The Nature of Technology. Free Press.

ARTHUR, B. (1989). Competing Technologies, Increasing Returns and Lock in by Historical Events, The Economic Journal, 99: ||6-|3|.

AYLEN, J. (20I0). Open versus closed innovation: development of the wide strip mill for steel in the United States during the 1920s, R\&D Management, 40(I): 67-80.

BALDWIN, C. Y. and Clark, K. B. (2000) .Design Rules: the Power of Modularity Volume I. MIT Press.

BALDWIN, C. Y. and Clark, K. B. (1997) .Managing in the Age of Modularity. Harvard Business Review Sept/Oct: 8I-93.

CHESBROUGH, H. (2003) .Open Innovation: The New Imperative for Creating and Profiting from Technology. Harvard Business School Press, Cambridge, MA.

CHESBROUGH, H. and A. K.Crowther (2006). Beyond high tech: early adopters of open innovation in other industries, R\&D Management, 36, 3 (June): 229-236.

CHRISTENSEN, J. F., Olesen, M. H. and Kjær, J.S. (2005). The Industrial Dynamics of Open Innovation - Evidence from the transformation of consumer electronics. Research Policy, 34(I0): I533-1549.

COHEN and Levinthal (1990). Absorptive capacity: A new perspective on learning and innovation, Administrative Science Quarterly, Volume 35, Issue I pg. I28-I52.
CLARK, K. B.; Fujimoto, T. (199I) .Product development performance: strategy, organization and management in the world auto industry. Boston, Mass.: Harvard Business School Press.

DAVID, P. (1985). Clio and the Economics of Qwerty, The American Economic Review, 75(2), Papers and Proceedings of the Ninety-Seventh Annual Meeting of the American Economic Association, pp : 332-337.

DODGSON, M., Gann, D., \& Salter, A. (2006). The role of technology in the shift towards open innovation: The case of Procter \& Gamble. R\&D Management, 36(3), 333-346.

DYER, J.H. and Nobeoka, K. (2000) . Creating and Managing a High Performance Knowledge Sharing Network: The Toyota Case. Strategic Management Journal, 21: 345-67.

ECONOMIDES, N., and Salop, S. C. (1992) .Competition and Integration among Complements, and Network Market Structure. Journal of Industrial Economics, 40(I): I05-I23.

EVANS D.S., Hagiu, A. and Schmalensee, R. (2006) .Invisible Engines: How Software Platforms Drive Innovation and Transform Industries, Massachusetts Institute of Technology, MIT Press.

FLEMING L. and Sorenson, O. (2003) .Navigating the Technology Landscape of Innovation. MIT Sloan Management Review, 44(2): I5-23.

GARUD, R. and Kumaraswamy, A. (1993) .Changing competitive dynamics in network industries: An exploration of Sun Microsystems' open systems strategy. Strategic Management Journal , 14: 35I-369.

GAWER, A. and Cusumano, M. (2002) Platform Leadership, Harvard Business School Press.

GASSMANN, Oliver (2006). Opening up the innovation process: towards an agenda. R\&D Management, 36(3): 223-226.

HARGADON, A. and Sutton, R. (1997). Technology brokering and innovation in a product development firm. Administrative Science Quarterly, 42(4): 716-749. 
HAGEDOORN, J. (1993) .Understanding the Rationale of Strategic Technology Partnering: Inter-organizational Modes of Cooperation and Sectoral Differences. Strategic Management Journal, 14: 37I-85.

HENDERSON, R. M., and Clark, K. B. (1990). Architectural innovation: The reconfiguration of existing product technologies and the failure of established firms. Administrative Science Quarterly, 35(I): 9-20.

HILL, C. (1997). Establishing a Standard: competitive strategy and technological standards in winner-take-all industries, Academy of Management Executive, II(2): 7-25.

KATZ M. L., and Shapiro C. (1985) .Network externalities, competition, and compatibility. American Economic Review 75: 424-440.

KEMP, S. (200I) The Ultimate History of Video Games, Three Rivers Press, New York.

LANGLOIS, R. N. and Robertson, P.L (1992) .Networks and innovation in a modular system: lessons from the microcomputer and stereo component industries. Research Policy, 21: 297-313

LEONARD, D. (1998) Wellsprings of Knowledge, Harvard Business School Press.

MANN, C. (2009). Beyond Detroit: On the Road to Recovery, Let the Little Guys Drive, Wired, 17(6).

MARCH, J. (199I) .Exploration and Exploitation in Organizational Learning. Organization Science, 2: 7I-87.

MEYER, M.H. P. Tertzakian, and J.M. Utterback (1997) .Metrics of Managing Product Development. Management Science, 43(I):88-III.

MIKKOLA, J. H. (2003) .Modularity, component outsourcing, and inter-firm learning. R\&D Management, 33(4): 439-454.

NAKAMURA and Ohashi, (2008). Effects of User Innovation on Industry Growth: Evidence from Steel Refining Technology, Working Paper series no:47, National Institute of Science and Technology Policy available at: www.nistep.go.jp/achiev/ftx/eng/dis047e/pdf/dis047e.pdf
NELSON, R. and Winter, S. (1982) .An Evolutionary Theory of Economic Change, Cambridge: Harvard University Press.

PAVITT, K.(2005) .Innovation Processes. in J. Fagerberg, D.C. Mowery and R.R. Nelson (eds.) The Oxford Handbook of Innovation, pp 86-II4, Oxford, UK? Oxford Universiy Press.

PORTER, M. (1998). Competitive Advantage: Creating and Sustaining Superior Performance, Free Press.

POWELL, W.W., Koput, K.W. and Smith-Doerr, L. (1996) . Interorganizational Collaboration and the Locus of Innovation: Networks of Learning in Biotechnology. Administrative Science Quarterly, 4I:II6-I45.

ROSENBERG, N. (1994).Exploring the Black Box : Technology, Economics and History, Cambridge, Cambridge University Press.

ROSENKOPF, L. and Tushman, M.L. (1998) .The Coevolution of Community Networks and Technology: Lessons From the Flight Simulation Industry. Industrial and Corporate Change, 7: 3II-46.

ROWLEY, T., Behrens, D. and Krackhardt, D., (2000) Redundant Governance Structures: An Analysis of Structural ad Relational Embeddedness in the Steel and Semiconductor Industries, Strategic Management Journal, 21:369-86.

SANCHEZ and J.T. Mahoney (1996) .Modularity, flexibility, and knowledge management in product and organizational design., Strategic Management Journal, 17, Winter special issue: 63--76.

SANCHEZ, M. an Collins, R.P. (200I) .Competing and Learning in Modular Markets. Long Range Planning, 34, $645--67$.

SANDERSON S. and M. Uzumeri (1995) .Managing product families: The case of the Sony Walkman. Research Policy, 24(5): 76I-782.

SCHILLING, M. (2008). Strategic Management of Technological Innovation, Mc Graw Hill, Singapore. 
SCHILLING, M. A. (2000) . Toward a General Modular Systems Theory and Its Application to Inter-firm Product Modularity. Academy of Management Review, 25(2): 312-334.

SCHILLING, M. (1999).Winning the standards race: Building installed base and the availability of complementary goods. European Management Journal, (I7): 3, 265-274.

SHAN, W., G. Walker; B. Kogut (1994) Interfirm Cooperation and Startup Innovation in the Biotechnology Industry Strategic Management Journal, 15(5): 387-394.

SIMON, H. (1962) .The Architecture of Complexity. Proceedings of the American Philosophical Society, 106(6): 467-82.

SOBRERO, M. and Roberts, E. (2002) .Strategic management of supplier-manufacturer relations in new product development. Research Policy, 3I(I):I59.

ULRICH (1995). The Role of Product Architecture in the Manufacturing Firm. Research Policy, 24: 419-40.

UZZI, B. (1997).Social Structure and Competition in Interfirm Networks: The Paradox of Embeddedness, Administrative Science Quarterly, 42(I): 35-67.

UTTERBACK, J., Vedin, B.A., Alvarez, E., Ekman, S., Sanderson, S., Tether, B. and Verganti, R. (2006) .Design Inspired Innovation. World Scientific Publishing.

VON HIPPEL, Eric (1976) .The Dominant Role of Users in the Scientific Instrument Innovation Process. Research Policy 5(3):212-39.

WALKER, G., Kogut B. and Shan W. (1997) Social Capital Structural Holes and the Formation of an Industry Network, Organization Science, 8(2): 109.

WEST, J. and Scott G. (2006). Challenges of open innovation: the paradox of firm investment in open-source software. R\&D Management, 36, (3): 319-331.

WOMACK, J.P., Jones, D. T. and Roos, D. (1990) .The Machine That Changed the World : The Story of Lean Production. Scribner Press. 